\title{
Paraneoplastic Limbic Encephalitis
}

\author{
J.M.S. Pearce \\ Emeritus Consultant Neurologist, Department of Neurology, Hull Royal Infirmary, Hull, UK
}

Paraneoplastic neurological syndromes are associated with neoplasia but are neither caused by the tumour nor by metastases in the nervous system. By definition, they are not caused by metabolic complications, secondary infections, nutritional disorders or toxicity of chemotherapy. Oppenheim [1], that greatly undervalued 19th century neurologist, was probably the first to associate cancer and neurological disease [2], discussing 'brain symptoms in carcinomatosis without demonstrable lesions in the brain', which he shrewdly considered the result of a toxic process. Auché [3] was the first to describe peripheral neuropathy in a patient with cancer.

Among these syndromes [4], clinically the most important (table 1) are cerebellar degeneration, sensory neuropathy, Lambert-Eaton myasthenic syndrome, opsoclonus-myoclonus syndrome and encephalomyelitis. An original account of the sensory neuropathy complicating carcinoma was given by Denny-Brown in 1948 [5].

\section{Paraneoplastic Limbic Encephalitis}

In 1960, Brierley et al. [6] gave a seminal account of 3 patients suffering from 'subacute encephalitis of later adult life mainly affecting the limbic areas'. At autopsy, the first patient had a leiomyoma of the left kidney but no other evidence of malignancy. The second patient had several mediastinal and hilar lymph nodes 'extensively replaced by oat-shaped cells, appearing identical to those seen in anaplastic bronchial carcinoma'; no tumour was found in the lungs or elsewhere. Their third patient had 'an encapsulated mass at the root of the right lung', which consisted of fibrotic lymph nodes. Although in 1956 Charatan and Brierley [7] had previously reported patients with a 'mental disorder associated with primary lung carcinoma', interestingly, they concluded that it was 'most unlikely that this finding (lung cancer in patient 2) is in any way related to the encephalitis but its occurrence should be noted'. They did recognize that a lung cancer had been clinically suspected in patient 3. In 1961, Verhaart [8] described 2 patients with inflammatory lesions of the medial temporal lobe and nerve cell loss in the brainstem and cerebellum, both of whom had tumour in the mediastinal lymph nodes but no proven lung lesion. In 1962, Störring et al. [9] described an 'undifferentiated bronchial carcinoma and an encephalitic-like picture in the limbic system'. Yahr et al. [10] reported a patient with 'encephalopathy associated with carcinoma' who had small-cell lung cancer (SCLC) and limbic system inflammatory changes. In 1967, Ulrich et al. [11] described SCLC and neuronal degeneration in Ammon's horn with some perivascular lymphocytic cuffing.

However, it was Corsellis et al. [12], who, in 1968, applied the term 'limbic encephalitis'. They reported 3 additional patients and extensively reviewed the literature [12]. More reports followed and established the syndrome

\section{KARGER \\ Fax +41613061234 E-Mail karger@karger.ch} www.karger.com
(C) 2005 S. Karger AG, Basel 0014-3022/05/0532-0106\$22.00/0

Accessible online at: www.karger.com/ene
J.M.S. Pearce

304 Beverley Road

Anlaby, East Yorks HU10 7BG (UK) 
Table 1. Pathological classification of paraneoplastic syndromes

\begin{tabular}{lllc}
\hline Involving the CNS & Involving the PNS & Involving both CNS and PNS & Involving neuromuscular junction \\
\hline $\begin{array}{c}\text { Paraneoplastic cerebellar } \\
\text { degeneration }\end{array}$ & $\begin{array}{c}\text { Sensorimotor neuropathy } \\
\text { Autonomic neuropathy } \\
\begin{array}{c}\text { Opsoclonus-myoclonus } \\
\text { retinopathy }\end{array}\end{array}$ & $\begin{array}{c}\text { Paraneoplastic } \\
\text { encephalomyelitis/ } \\
\text { Sensory neuropathy }\end{array}$ & $\begin{array}{c}\text { Lambert-Eaton myasthenic } \\
\text { syndrome (LEMS) }\end{array}$ \\
\hline
\end{tabular}

so that by 1990 Bakheit et al. [13] detailed 3 new cases and found 16 that had been verified clinically and pathologically.

Paraneoplastic limbic encephalitis (PLE) typically affects the mesial temporal lobe and limbic mesial cortical structures (cingulate gyrus, orbitofrontal cortex and mamillary bodies) and causes prominent memory and personality disturbances and seizures. SCLC is the most commonly associated neoplasm, but many other neoplasias have been identified $[5,6,8,9]$. Neurological symptoms usually precede the diagnosis of cancer, but the diagnosis is more difficult in patients who present with insidious cognitive or psychiatric dysfunction without obvious signs of cancer. Three hypotheses evolved: (i) an undefined degeneration in which the inflammatory infiltrates were secondary to the 'tissue breakdown' $[9,12]$; (ii) a viral infection [12], and (iii) Dorothy Russell's prescient idea of an immune-mediated response against the nervous system [14]. The last hypothesis is presently accepted.

\section{Diagnosis}

The diagnosis of PLE remains difficult since presenting symptoms may be atypical. Current studies show a striking female preponderance, patients mainly in their sixth decade and above, and a median survival of 43 months.

Electro-encephalography shows focal or generalized slowing and/or epileptiform activity, maximal in the temporal regions. A negative CSF cytology for malignant cells and a lack of meningeal enhancement on MRI helps to exclude leptomeningeal deposits, but pleocytosis and oligoclonal bands support an immune-mediated disorder such as PLE. In the differential diagnosis, similar symptoms can arise from Wernicke's encephalopathy, herpes simplex encephalitis, multiple sclerosis and systemic lupus erythematosus.

The majority of patients with paraneoplastic neurological disorders are not known to have cancer at the time of diagnosis $[15,16]$. Neuronal autoantibodies that have been reported as markers include antineuronal nuclear antibody type 1 (anti-Hu), amphiphysin, collapsin response mediator protein $5 \mathrm{IgG}$, Purkinje cell cytoplasmic autoantibody type 2, antineuronal nuclear antibody type 3, anti-Ma, P/Q-type calcium channel antibodies and Ntype calcium channel antibodies. No pathogenic relationship has been established between PLE and any specific antibody; some reported cases are not associated with a marker autoantibody despite a typical clinical course and the detection of SCLC.

Patients with anti-Hu antibodies usually have SCLC (94\%), multifocal neurological symptoms and a poor prognosis. Paraneoplastic neurological disease antigens are proteins normally expressed specifically in neurons that are expressed ectopically in tumours. It is believed that when expressed in tumours outside the immunologically privileged nervous system, paraneoplastic neurological disease antigens stimulate the development of antitumour immunity, but also stimulate an autoimmune neuronal degeneration.

\section{Differential Diagnosis}

Although $80 \%$ of patients with SCLC have antibodies, for other neoplasms the incidence is about $50 \%$. Increasing experience showed that anti-Ma2-associated encephalitis differs from classical paraneoplastic limbic or brainstem encephalitis and may be unrecognized [17]. Anti-Ma2 encephalitis is characterized by limbic, diencephalic or brainstem dysfunction, vertical gaze paresis, with MRI abnormalities in these regions, and inflammatory changes in the CSF. In young male patients, the primary tumour is usually in the testis; in others, the most common neoplasms are lung and breast cancer, though many malignancies have been indicted. Neurological symptoms distant from the limbic system, in the brainstem and cerebellum are common in patients with PLE. In $80 \%$ of the cases, MRI shows an increased $\mathrm{T}_{2}$-weighted signal involv- 
ing one or both mesial temporal limbic structures and insular cortex, without gadolinium enhancement [18]. But in the early stages of herpes simplex encephalitis, similar signs can be confusing until oedema and gyral enhancement or haemorrhagic changes supervene.
The prognosis depends on the biological aggressiveness of the underlying neoplasm in most instances. Treatment is generally ineffective, but prednisone, chemotherapy, high-dose intravenous immunoglobulin, irradiation or plasmapheresis can provide temporary remission.

\section{References}

1 Pearce JMS: Hermann Oppenheim (18581919). J Neurol Neurosurg Psychiatry 2003; 74:569.

2 Oppenheim H: Über Hirnsymptome bei Carcinomatose ohne nachweisbare Veränderungen im Gehirn. Charité-Annalen (Berlin) 1888; 13:335-344.

3 Auché M: Des névrites périphériques chez les cancéreux. Rev Méd 1890;10:785-807.

4 Henson RA, Urich H: Cancer and the Nervous System. Oxford, Blackwell Scientific Publications, 1982.

5 Denny-Brown D: Primary sensory neuropathy with muscular changes associated with carcinoma. J Neurol Neurosurg Psychiatry 1948; 11:73-87.

6 Brierley JB, Corsellis JAN, Hierons R, et al: Subacute encephalitis of later adult life mainly affecting the limbic areas. Brain 1960;83:357368.

7 Charatan FB, Brierley JB: Mental disorder associated with primary lung carcinoma. Br Med J 1956;i:765-768.
8 Verhaart WJC: Grey matter degeneration of the CNS in carcinoma. Acta Neuropathol (Berl) 1961;1:107-112.

9 Störring G, Hauss K, Ule G: Zur topischen Diagnostik des anamnestischen Symptomenkomplexes. Psychiatr Neurol (Basel) 1962;143: 161-177.

10 Yahr MD, Duvoisin RC, Cowen D: Encephalopathy associated with carcinoma. Trans Am Neurol Assoc 1965;90:80-86.

11 Ulrich J, Spiess H, Huber R: Neurological syndrome as a remote effect of a malignant tumor (Ammon's horn sclerosis in bronchial carcinoma). Schweiz Arch Neurol Neurochir Psychiatrie 1967;99:83-100.

12 Corsellis JA, Goldberg GJ, Norton AR: 'Limbic encephalitis' and its association with carcinoma. Brain 1968;91:481-496.

13 Bakheit AM, Kennedy PG, Behan PO: Paraneoplastic limbic encephalitis: Clinico-pathological correlations. J Neurol Neurosurg Psychiatry 1990;53:1084-1088.
14 Russell DS: Encephalomyelitis and 'carcinomatous neuropathy'; in van Bogaert L, Radermecker J, Hozay J, Lowenthal A (eds): Encephalitides. Amsterdam, Elsevier, 1961, pp 131-135.

15 Candler PM, Hart PE, Barnett M, Weil R, Rees JH: A follow-up study of patients with paraneoplastic neurological disease in the United Kingdom. J Neurol Neurosurg Psychiatry 2004; 75:1411-1415.

16 Gultekin SH, Rosenfeld MR, Voltz R, Eichen J, Posner JB, Dalmau J: Paraneoplastic limbic encephalitis: Neurological symptoms, immunological findings and tumour association in 50 patients. Brain 2000;123:1481-1494.

17 Dalmau J, Graus F, Villarejo A, Posner JB, Blumenthal D, Thiessen B, Saiz A, Meneses P, Rosenfeld MR: Clinical analysis of anti-Ma2associated encephalitis. Brain 2004; 127:18311844.

18 Lawn ND, Westmoreland BF, Kiely MJ, Lennon VA, Vernino S: Clinical, magnetic resonance imaging, and electroencephalographic findings in paraneoplastic limbic encephalitis. Mayo Clin Proc 2003;78:1363-1368. 